\title{
Isolated Limb Perfusion for In-Transit Melanoma Metastases: Melphalan or TNF-Melphalan Perfusion?
}

\author{
HARALD J. HOEKSTRA, * KELLY VEERMAN, AND ROBERT J. VAN GINKEL \\ Department of Surgical Oncology, University Medical Center Groningen, University of Groningen, Groningen, The Netherlands
}

\begin{abstract}
Indications for treatment of melanoma in-transit metastases (ITMs) confined to the limb with isolated limb perfusion (ILP) are not well defined. This study reports the Groningen regional therapeutic perfusion experience with melphalan (M-ILP) and TNF-melphalan (TM-ILP) for ITMs, and reviews of the melanoma TNF-melphalan ILP literature. Between 1991 and 2012, 60 patients were treated with ILP. Patients with "small" ITMs received M-ILP (10-13 mg melphalan/L limb volume) and patients with "bulky" disease TM-ILP (1-4 mg TNF); 19 M-ILPs and 41 TM-ILPs were performed, 26 Stage IIIB, 31 Stage IIIB and 1 stage IV disease. Overall response after 57 ILPs was 90\%; CR 27 (45\%), PR 27 (45\%), no response 3 (5\%); after 9 M-ILPs CR 6 (32\%) and 41 TM-ILPs CR $21(51 \%, P=0.124)$. For younger patients ( $<65$ years) CR was $69 \%$ and for elderly patients $29 \%(P=0.003)$. For low volume disease $(<5$ ITMs $) \mathrm{CR}$ was $75 \%$ and for high volume disease $(\geq 5 \mathrm{ITMs}) 41 \%(P=0.038)$. After median follow-up of 15 months (range, 1-144) there was local recurrence or disease progression in 36 patients (60\%). Positive lymph node status was associated with local progression, absence of CR and Stage IIIC disease; these were independent prognostic factors for progression to systemic disease. M-ILP is an effective regional treatment for melanoma ITMs, whereas for bulky disease TM-ILP should be the first choice. In-field progression-free survival after ILP is determined by the biological behavior of the ITMs and the patient's immune system.
\end{abstract}

J. Surg. Oncol. 2014;109:338-347 (c) 2014 Wiley Periodicals, Inc.

KEY WoRDs: melanoma; perfusion; in-transit metastases; regional chemotherapy; melphalan; TNF $\alpha$

\section{INTRODUCTION}

Although most types of cancers are declining in incidence, melanoma incidence has increased steadily worldwide over the last 20 years. In the Netherlands the incidence rate increased over the last decade from 17.3 per 100,000 in 2002 to 30.4 per 100,000 in 2011 . The increased incidence has been especially in the elderly [1]. The current melanoma incidence in the USA is 21.1 per 100,000 , while the highest incidence rate of 49.8 per 100,000 is in Australia [2,3].

The first presentation of melanoma is as localized disease in $84 \%$ of patients, in regional lymph nodes in $9 \%$, as metastatic disease in $4 \%$ and unknown stage in $4 \%$, with relative 5 year survival rates of $98.3 \%$, $62.4 \%, 16 \%$, and $76.5 \%$, respectively [1,2]. Of all primary melanomas $50 \%$ are located on the limbs (30\% lower limb and $20 \%$ upper limb), $36 \%$ on the trunk and $14 \%$ in the head and neck region [1].

The treatment for primary melanoma, regional and/or distant disease is well defined in the various national melanoma management guidelines with respect to surgical margins, sentinel lymph node biopsy (SLNB), radiation therapy, immunotherapy, chemotherapy, drug targeting therapy and follow-up [4]. Melanoma is currently one of the most survivable cancers, although the behavior of individual melanomas is unpredictable. Important prognostic factors for disease-free survival are Breslow thickness, presence or absence of ulceration, mitotic rate, gender, and body site [5].

According to the incubator hypothesis the lymphatic route is the principal method of spread of melanomas from their original site to the lymph node field where the metastatic melanoma cells may survive and grow slowly or remain latent before, in some patients, spreading to distant sites [6]. The risk of developing in-transit metastases (ITMs) is higher if the pathology shows lymphatic invasion in the primary tumor [7]. Another risk factor is a high tumor mitotic rate (TMR) in the primary tumor [8]. Ultimately, 3-5\% of melanoma patients will develop local recurrence or ITMs, 5-13\% regional disease and 3-10\% distant disease [9]. The median time to the development of ITMs is 13-16 months after initial adequate local excision of the melanoma [9].
Adjuvant isolated limb perfusion (ILP) with melphalan (M-ILP) did not prevent local and/or regional ITMs, or influence disease-free or overall survival in melanoma confined to a limb [10]. The risks of local recurrence or ITMs after wide local excision in the EORTC perfusion trial (18832) were $2.9 \%$ and $6.6 \%$, respectively [10].

Melanomas that recur locally may be curable by wide local excision and those that have spread to regional lymph nodes may be curable with therapeutic lymph node dissection [11]. Although melanomas that have spread to distant sites are rarely curable, a small proportion of patients can be cured by surgical resection of all metastatic disease, with 5-year survival rates of up to $39 \%[12,13]$.

Dacarbazine (DTIC), approved since 1970, was until recently the most effective drug for unresectable disease, with response rates of 10 $20 \%$ but no significant improvement in survival. Recently, two different treatment approaches, immunotherapy with a monoclonal antibody against cytotoxic-T-lymphocyte-associated antigen 4 (CTLA-4 (ipilimumab)) and molecular/drug-targeted therapy with a BRAF and/ or a MEK inhibitor produced improvement in progression-free survival (PFS) and overall survival (OS) in melanoma patients with Stage IV disease [14-16]. Current studies are exploring the safety and effectiveness of the anti programmed cell death 1 (PD-1) receptor (anti-PD-1) in the treatment of advanced melanoma [17].

*Correspondence to: H.J. Hoekstra, Department of Surgical Oncology, University Medical Center Groningen, University of Groningen, PO Box 30.001, 9700 RB Groningen, The Netherlands. Fax: 31-50-3611745. E-mail: h.j.hoekstra@umcg.nl

Received 08 July 2013; Accepted 05 December 2013

DOI 10.1002/jso.23552

Published online 9 January 2014 in Wiley Online Library (wileyonlinelibrary.com) 


\section{In-Transit Metastases}

The treatment of ITMs is less straightforward. ITMs are tumor emboli trapped in the lymphatics between a primary tumor and the regional lymph node basin. It has been suggested that elective lymph node dissection, sentinel lymph node biopsy or completion lymph node dissection increase the risk of development of ITMs. However, the risk of ITMs depends on the tumor biology and not to the surgical approach to the regional nodes [18]. Although ITMs can occur in any part of the body, the majority are diagnosed in the lower limb. It has been suggested that the higher incidence of ITMs in the lower limb may be caused by gravity and delayed lymphatic drainage.

The current management options for ITMs are local treatment, regional treatment or systemic treatment (Fig. 1). Isolated limb infusion (ILI) or isolated limb perfusion (ILP) with melphalan, M-ILI and M-ILP, are effective locoregional treatments for ITMs $[19,20]$. To further improve the outcome of ILP other drugs such as dacarbazine (DTIC), melphalan in combination with actinomycin C, adriamycin, mitomycin-C, thiothepa, cisplatin, carboplatin have been used to treat ITMs, but their effectiveness was limited or the local toxicity too high and they have therefore been abandoned in the perfusion setting $[21,22]$.

\section{Tumor Necrosis Factor Alpha}

Twenty-five years ago Lejeune [23] explored the use of high-dose tumor necrosis factor-alpha ( $\mathrm{TNF} \alpha$ ), interferon-gamma (IFN-) and melphalan in the ILP treatment (TM-ILP) of ITMs. After a small multicenter pilot study it was concluded a few years later that TM-ILP was the treatment of choice for in-transit melanoma metastases [24]. In a multi-center study ILP with $\mathrm{TNF} \alpha\left(\right.$ Beromun $\left.^{\mathbb{R}}\right)$ and melphalan was successfully investigated as a limb-saving treatment for locally advanced sarcomas [25,26]. The European Medicine Agency (EMA) approved Beromun ${ }^{\circledR}$ for irresectable sarcomas and "bulky melanoma," so called "melanosarcomas," in 1999 [27].

This article reports the Groningen ILP experience with therapeutic perfusions with M-ILP and TM-ILP for melanoma ITMs, and reviews the current status of TM-ILPs as reported in the literature.

\section{PATIENTS AND METHODS}

\section{Patients}

Between 1991 and 2012, 60 patients with ITMs were treated with ILP in Groningen, median age 65 (range 33-84) years, 14 males (23\%) and 46 females (77\%). Patients with "small" (low volume) ITMs were treated with melphalan ILP (M-ILP), whereas patients with "bulky" (high volume) disease were treated with TNF $\alpha$ and melphalan ILP (TM-ILP). There were 19 M-ILPs (32\%) and 41 TM-ILPs $(68 \%)$ performed. Patient, tumor/disease characteristics and AJCC stage of disease are summarized in Table I.

\section{Perfusion Treatment}

Lower limb ILP was performed at three different levels (iliac, inguinal (femoral), and popliteal), and upper limb ILP at two levels (axillary or brachial), depending on the anatomical location of the ITMs (Fig. 2). Isolation of the blood supply of the limb was achieved by clamping and cannulating the major artery and vein after heparinization of the patient, connection to the oxygenated extracorporeal circuit, ligation of collateral vessels, and application of a tourniquet at the root of the limb to occlude superficial veins.

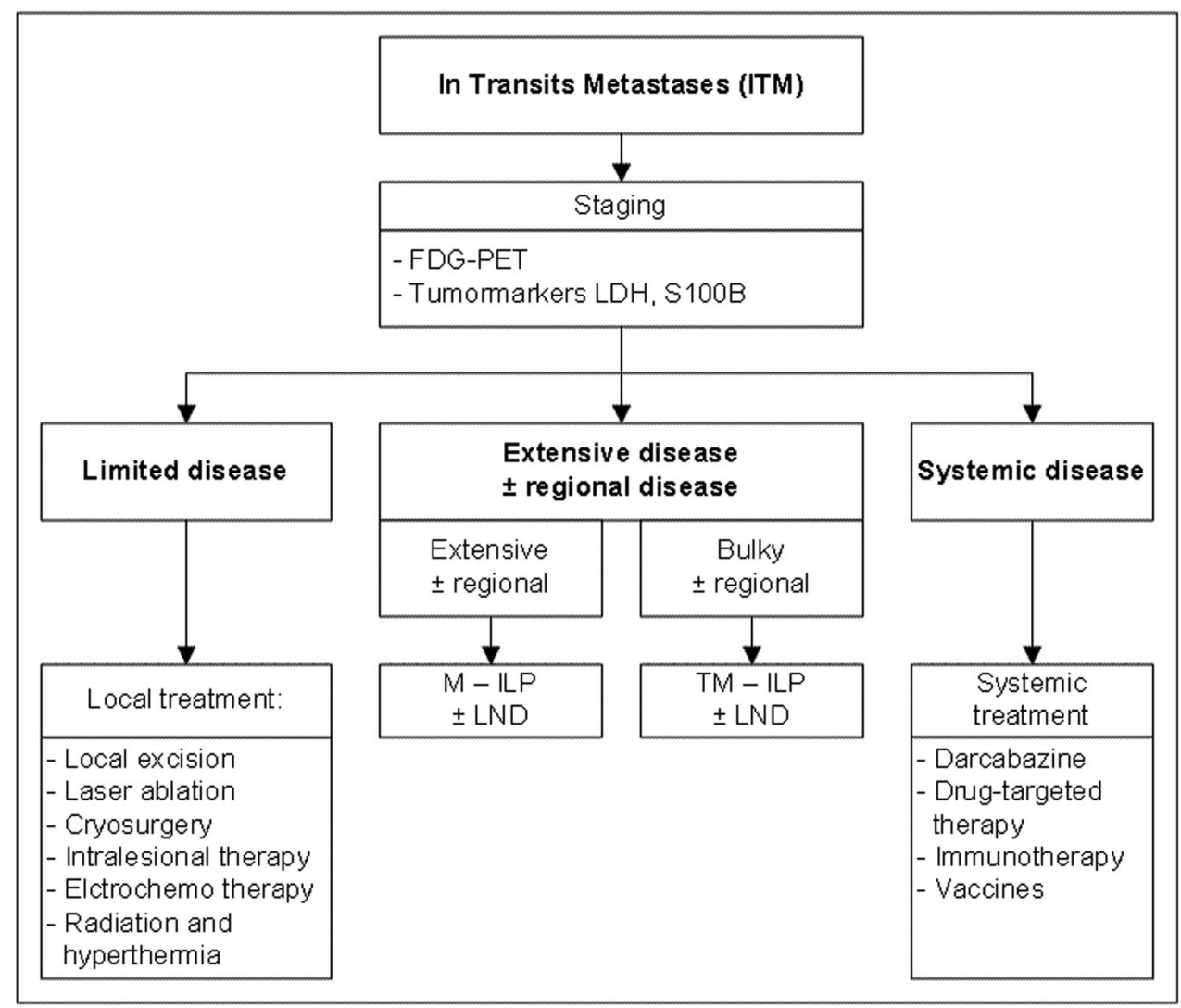

Fig. 1. Treatment options in-transit metastases (ITMs). 
TABLE I. Patient and Tumor Characteristics

\begin{tabular}{|c|c|c|c|c|}
\hline & $\begin{array}{c}\text { Melphalan }(\mathrm{n}=19) \\
(\text { No, \% })\end{array}$ & $\begin{array}{c}\text { Melphalan }+ \text { TNF- } \alpha(\mathrm{n}=41) \\
(\mathrm{No}, \%)\end{array}$ & $\begin{array}{l}\text { Total }(\mathrm{n}=60) \\
(\text { No, } \%)\end{array}$ & $P$-value \\
\hline \multicolumn{5}{|l|}{ Gender } \\
\hline Male & $5(26 \%)$ & $9(22 \%)$ & $14(23 \%)$ & \multirow[t]{2}{*}{0.479} \\
\hline Female & $14(74 \%)$ & $32(78 \%)$ & $46(77 \%)$ & \\
\hline \multicolumn{5}{|l|}{ Age } \\
\hline Median in years (range) & $62(33-80)$ & $65(39-84)$ & $65(33-84)$ & 0.556 \\
\hline$<65$ years & $10(53 \%)$ & $18(44 \%)$ & $28(47 \%)$ & \multirow[t]{2}{*}{0.586} \\
\hline$\geq 65$ years & $9(47 \%)$ & $23(56 \%)$ & $32(53 \%)$ & \\
\hline \multicolumn{5}{|l|}{ Location PT } \\
\hline Arm & $1(5 \%)$ & $2(5 \%)$ & $3(5 \%)$ & \multirow[t]{4}{*}{0.998} \\
\hline Leg & $17(90 \%)$ & $36(88 \%)$ & $53(88 \%)$ & \\
\hline Unknown primary & $1(5 \%)$ & $2(5 \%)$ & $3(5 \%)$ & \\
\hline Other & $0(0 \%)$ & $1(2 \%)$ & $1(2 \%)$ & \\
\hline \multicolumn{5}{|l|}{ Breslow thickness } \\
\hline Median in mm (range) & $2.70(0.70-16.0)$ & $2.60(0.80-10.5)$ & $2.60(0.70-16.0)$ & 0.903 \\
\hline \multicolumn{5}{|l|}{ Ulceration } \\
\hline Present & $6(32 \%)$ & $14(34 \%)$ & $20(33 \%)$ & \multirow[t]{3}{*}{0.412} \\
\hline Absent & $10(53 \%)$ & $15(37 \%)$ & $25(42 \%)$ & \\
\hline Unknown & $3(15 \%)$ & $12(30 \%)$ & $15(25 \%)$ & \\
\hline \multicolumn{5}{|l|}{ PT histology } \\
\hline SSM & $7(37 \%)$ & $11(27 \%)$ & $18(30 \%)$ & \multirow[t]{4}{*}{0.629} \\
\hline Nodular & $6(32 \%)$ & $10(24 \%)$ & $16(27 \%)$ & \\
\hline Acral lentiginous & $1(5 \%)$ & $2(5 \%)$ & $3(5 \%)$ & \\
\hline Other/unknown & $5(26 \%)$ & $18(44 \%)$ & $23(38 \%)$ & \\
\hline \multicolumn{5}{|l|}{ Interval PT and ITMs ${ }^{\mathrm{a}}$} \\
\hline$<12$ months & $9(50 \%)$ & $17(45 \%)$ & $26(46 \%)$ & \multirow[t]{2}{*}{0.466} \\
\hline$\geq 12$ months & $9(50 \%)$ & $21(55 \%)$ & $30(54 \%)$ & \\
\hline \multicolumn{5}{|l|}{ Interval ITMs and ILP ${ }^{\mathrm{b}}$} \\
\hline$<3$ months & $7(37 \%)$ & $18(45 \%)$ & $25(42 \%)$ & \multirow[t]{2}{*}{0.380} \\
\hline$\geq 3$ months & $12(63 \%)$ & $22(55 \%)$ & $34(58 \%)$ & \\
\hline \multicolumn{5}{|l|}{ Location ITMs ${ }^{\mathrm{b}}$} \\
\hline Arm & $1(5 \%)$ & $2(5 \%)$ & $3(5 \%)$ & \multirow[t]{2}{*}{0.653} \\
\hline Leg & $18(95 \%)$ & $38(95 \%)$ & $56(95 \%)$ & \\
\hline \multicolumn{5}{|l|}{ Number of ITMs } \\
\hline Median (range) & $19(4-35)$ & $12(1-40)$ & $15(1-40)$ & 0.148 \\
\hline \multicolumn{5}{|l|}{ AJCC stage } \\
\hline IIIB & $10(53 \%)$ & $16(39 \%)$ & $26(43 \%)$ & \multirow[t]{3}{*}{0.591} \\
\hline IIIC & $8(42 \%)$ & $23(56 \%)$ & $31(52 \%)$ & \\
\hline IV & $1(5 \%)$ & $2(5 \%)$ & $3(5 \%)$ & \\
\hline
\end{tabular}

PT, primary tumor; SSM, superficial spreading melanoma; ITMs, in-transit metastases; ILP, isolated limb perfusion; AJCC stage, American Joint Committee on Cancer. ${ }^{a}$ Analysis on 56 patients: three missing because of unknown primary tumor. In one patient stage IV without ITMs indicated ILP.

${ }^{\mathrm{b}}$ Analysis on 59 patients: in one patient stage IV without IT-metastases indicated ILP.

The pressure-regulated perfusion was performed under mild hyperthermia $\left(38.5-40^{\circ} \mathrm{C}\right)$ with an extracorporeal circuit flow rate of approximately $500 \mathrm{ml} / \mathrm{min}$ [28]. The extremity was wrapped in a heating blanket to maintain optimal temperature. Temperature was monitored

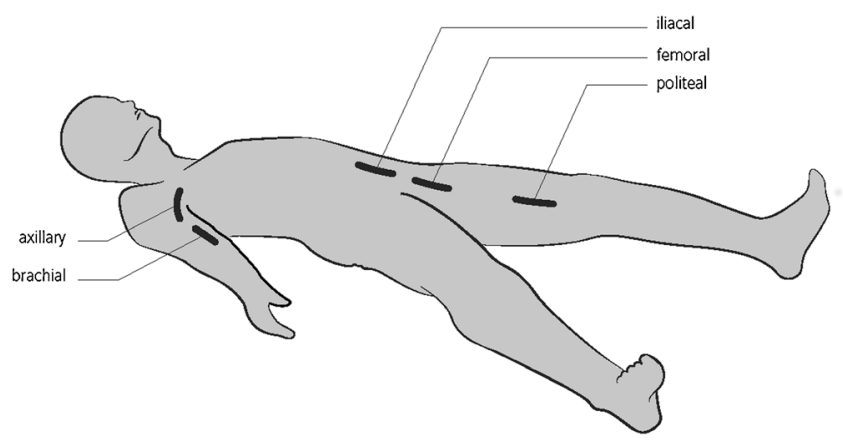

Fig. 2. Perfusions levels. with thermistors. Leakage from the limb to the systemic circulation was monitored with radio-labeled 131-I human serum albumin using a precordial scintillation probe [29] (Fig. 3).

The perfusion time for M-ILP was $60 \mathrm{~min}$, for TM-ILP $15 \mathrm{~min}$ with TNF $\alpha$, and 45 min with mephalan. The dosage of melphalan was based on limb volume, $10 \mathrm{mg} / \mathrm{L}$ lower limb volume and $13 \mathrm{mg} / \mathrm{L}$ upper limb volume (Alkeran ${ }^{\circledR}$, Burroughs Wellcome LTD., London, UK) [30]. The dosage of TNF $\alpha$ (Boehringer Ingelheim International GMbH, Ingelheim am Rhein, Germany) was 1-2 mg for the lower extremity (iliac/femoral ILP $2 \mathrm{mg}$, popliteal ILP $1 \mathrm{mg}$ ) and $1 \mathrm{mg}$ for the upper extremity. The perfusion was stopped after $60 \mathrm{~min}$ and the extremity washed out with 3 $6 \mathrm{~L}$ saline and filled, if indicated, with one unit red blood cell concentrate. Catheters were removed, vessels repaired, and heparin neutralized with protamine sulphate. The operative and technical details of the ILP procedure have recently been updated and described in detail $[29,31]$.

A prophylactic, closed fasciotomy of the anterior compartment of the lower leg, or ventral and dorsal compartments of the forearm was performed through a $1 \mathrm{~cm}$ longitudinal incision of the skin in all patients to prevent a compartment syndrome. 


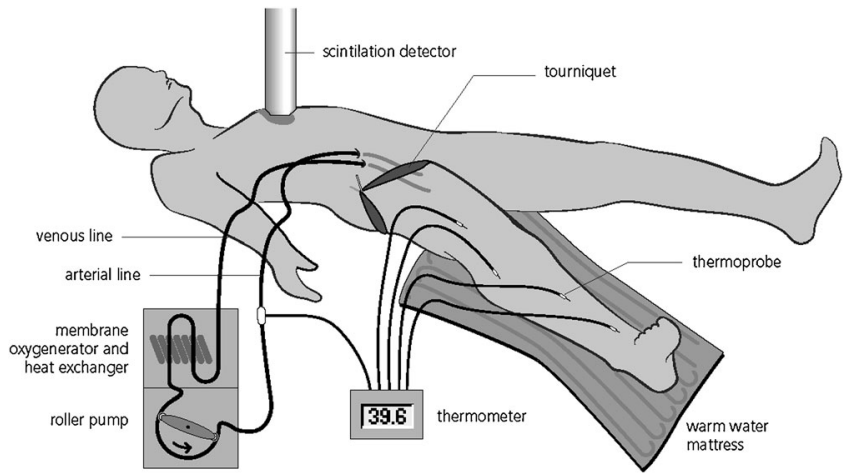

Fig. 3. Isolated regional perfusion.

\section{Response Rates and Toxicty}

Response rates were defined according to WHO toxicity criteria [32]. The treatment toxicity was recorded according the Wieberdink toxicity criteria [33] (Table II). Responses were assessed at 3 months after ILP and afterwards at 3-monthly intervals for the first year, 4-monthly intervals for the second year and at 6-monthly intervals thereafter.

\section{Statistical Evaluation}

Overall survival (OS), time to local progression (TLP) and time to systemic progression (TSP) were defined as the time between the ILP and death, local progression, or systemic progression, respectively. Survival curves were constructed by the Kaplan-Meier method and differences were assessed using the log-rank test. The Chi square test was used to calculate if there was a significant difference $(P<0.05)$ in the categorical variables between the M-ILPs and TM-ILPs. For continuous variables the Mann-Whitney $U$-test and the independent $t$ test were used, depending on the distribution of the variable. The Cox proportional hazards model was used to determine independent prognostic variables for TLP, TSP, and MSS. Prognostic variables for clinical response rate were determined by logistic regression analysis.

\section{RESULTS}

\section{Treatment}

In total 60 ILPs were performed, 19 with melphalan alone and 41 with melphalan plus TNF $\alpha ; 57$ (95\%) of the ILPs were for lower limb disease, and $3(5 \%)$ for upper limb disease. There were $21(35 \%)$ iliac, $8(13 \%)$ femoral, $28(47 \%)$ popliteal, and $3(5 \%)$ axillary perfusions. Iliac ILP was combined with deep groin dissection, femoral ILP with superficial groin dissection and axillary ILP with a level I-III axillary dissection. The median time between the diagnosis of ITM and ILP treatment was 4 (range, 0.3-66) months.

\section{TABLE II. Wieberdink Toxicity Scale}

\begin{tabular}{|c|c|}
\hline Grade & Clinical characteristics \\
\hline I & No subjective or objective evidence of reaction \\
\hline II & Slight erythema or edema \\
\hline III & $\begin{array}{l}\text { Considerable erythema or edema with some blistering; slightly disturbed } \\
\text { motility permissible }\end{array}$ \\
\hline IV & $\begin{array}{l}\text { Extensive epidermolysis or obvious damage to deep tissue causing } \\
\text { definite functional disturbances; threatened or manifest } \\
\text { compartmental syndrome }\end{array}$ \\
\hline $\mathrm{V}$ & Reaction that necessitates amputation \\
\hline
\end{tabular}

Perfusions were performed at a median maximum temperature of $40.0^{\circ} \mathrm{C}$ (range, $38.6-41.9^{\circ} \mathrm{C}$ ) with a median systemic leakage of $0.95 \%$ (range, $0-15 \%)$. A major leakage $(>10 \%)$ was encountered in three patients (5\%, Table III).

Some degree of acute regional toxicity was encountered in all patients after both M-ILPs and TM-ILPs: 38 Grade II (63\%), 17 Grade III (28\%), 4 Grade IV (7\%) and 1 Grade V (2\%) toxicity.

The median post-operative hospital stay after M-ILP was 9 (range, 434) days and after TM-ILPs 13 (range, 4-86) days (Table III); after axillary ILPs it was 14 (range, 5-15) days, after iliac ILPs 14 (range, 586) days, after femoral ILPs 23 (range, 9-66) days, and after popliteal ILPs 8 (range, 4-41) days.

\section{Complications}

There were two major perfusion-related complications requiring amputations; one after a severe technical perfusion pump-related complication with an air embolism and one after extensive tumor necrosis accompanied with severe infection of the limb, thus the initial limb salvage rate was $93 \%$. There was no peri- or post-perfusion mortality.

\section{Response Rates}

The clinical response could not be assessed in three patients (5\%), two who had amputation of the affected limb and one who was lost to follow up.

Three patients showed no response or progressive disease. The OR rate after 57 ILPs was $90 \%$, for respectively 16 M-ILPs (84\%) and 38 TM-ILPs (93\%). There were 27 CRs (45\%), 27 PRs (45\%), and 3 patients showed no response or progressive disease (5\%).

Eighteen M-ILPs resulted in 6 CRs (33\%) and 39 TM-ILPs in 21 CRs $(54 \%, P=0.124)$ Patients less than 65 years of age had a CR rate of $69 \%$ after ILP, compared to $29 \%$ in the elderly patients $(\geq 65$ years, $P=0.003)$. CR was observed in 9 patients $(75 \%)$ with low volume ITMs (1-5 ITMs), compared to 18 patients $(41 \%)$ with high volume ITMs ( $>5$ ITMs) $(P=0.038$, Table IV).

\section{Local Disease Control}

Local recurrence or disease progression occurred in 36 patients (63\%) after a median follow-up of 15 (range, 1-144) months; in 14 patients $(78 \%)$ after M-ILP with a median progressive free interval of 14 months and in 22 patients $(56 \%)$ after TM-ILP with a median progressive free interval of 16 months $(P=0.466)$.

Seventeen patients with a CR developed a local recurrence (63\%) after a median follow-up of 19 months, whereas 19 patients with a PR $(63 \%)$ developed progressive local disease after a median progressive free interval of 14 months $(P=0.584)$. This local disease progression necessitated amputation of the affected limb in two patients (3\%), after 24 and 95 months, respectively.

Positive lymph node status was associated with local progression and was the only significant prognostic factor for local progression in multivariable analysis $(P=0.036$, Table $\mathrm{V})$.

\section{Systemic Disease}

Of the 57 patients who underwent ILP for ITMs with curative intent systemic disease developed in 33 patients (55\%), after a median followup 40 (range 2-135) months, with no significant difference between the M-ILP and TM-ILP groups $(P=0.613)$. Of these 33 patients, 19 developed metastases in multiple locations $(58 \%)$ and in 14 patients the metastases were limited to one organ $(42 \%)$. The locations of distant metastases were lung (15), brain (7), bone (4), cutaneous (6), and intraabdominal (9). 
TABLE III. Perfusion Treatment Characteristics

\begin{tabular}{|c|c|c|c|}
\hline & Melphalan & Melphalan + TNF-á & Total \\
\hline \multicolumn{4}{|l|}{ Temperature } \\
\hline Median ${ }^{\circ} \mathrm{C}$ (range) & $39.8(38.6-40.7)$ & $40.0(38.6-41.9)$ & $40.0(38.6-41.9)$ \\
\hline \multicolumn{4}{|l|}{ Leakage } \\
\hline Median \% (range) & $0.90(0.00-12.00)$ & $1.10(0.00-15.00)$ & $0.95(0.00-15.00)$ \\
\hline $0-2 \%$ leakage & $12(71 \%)$ & $25(64 \%)$ & $37(66 \%)$ \\
\hline $2-10 \%$ leakage & $3(18 \%)$ & $13(33 \%)$ & $16(29 \%)$ \\
\hline Major leakage & $2(12 \%)$ & $1(3 \%)$ & $3(5 \%)$ \\
\hline \multicolumn{4}{|l|}{ Hospital stay } \\
\hline Median days (range) & $9(4-34)$ & $13(5-86)$ & $10(4-86)$ \\
\hline
\end{tabular}

Eleven CR patients (41\%) showed progression to systemic disease after a median follow up of 62 (range 2-67) months, and 21 PR patients $(70 \%)$ after a median follow up of 17 (range $2-135)$ months $(P=0.025)$, also significant in a multivariable analysis $(P=0.010$, Table V).

Patients with ulcerated primary melanomas developed systemic disease after a median time of 13 (range 2-62) months, compared to 67 (range 4-76) months for non-ulcerated primary melanomas $(P=0.007)$.

Patients with a short time interval ( $<12$ months) between the primary tumor treatment and development of ITMs had a median TSP of 13 (range 2-62) months in contrast to patients with a time interval of $>12$ months who had a median TSP of 56 (range $2-135)$ months $(P=0.035)$. In patients with an interval of $\geq 18$ months between primary tumor treatment and ILP a median TSP of 53 (range 2-13) months was observed, compared to 12 (range 2-62) months for patients with an interval $<18$ months $(P=0.038)$.

In multivariable analysis absence of $\mathrm{CR}$ and Stage IIIC disease were independent factors for progression to systemic disease (Table V).

\section{Melanoma-Specific Survival}

Fourteen M-ILP patients (74\%) and 14 TM-ILP patients (34\%) died of melanoma $(P=0.006)$. The median MSS for M-ILP/TM-ILP, Stage $\mathrm{IIIB} / \mathrm{C}$, treatment response, $\mathrm{CR} / \mathrm{PR}+\mathrm{NR}+\mathrm{PD}$ and ulceration status are presented in the Figure 4A-D.

The overall 1-year, 3-year, and 5-year MSS rates after ILP were respectively $89 \%, 65 \%$, and $39 \%$. The median MSS of the complete cohort was 52 (range, 1-173) months; 51 months after M-ILP and 68 months after TM-ILP (Fig. 4A, $P=0.196$ ). Median survival was 68 months for stage IIIB patients and 33 months for stage IIIC patients (Fig. 4B, $P=0.003$ ). The median MSS after CR was 68 months and after PR/NR/PD 38 months (Fig. 4C, $P=0.018$ ). The median MSS for ulcerated melanomas was 33 months and for non-ulcerated melanomas 83 months (Fig. 4D, $P=0.021$ ).

The 5-year MSS for patients with a short time interval ( $<12$ months) between primary melanoma treatment and development of ITMs was $15 \%$ and for patients with a longer time interval ( $\geq 12$ months) it was $60 \%(P=0.077)$
In the univariate analysis absence of ulceration, AJCC stage IIIB, and CR were prognostic factors for prolonged MSS. In the multivariable analysis AJCC stage and clinical response rate were the two significant prognostic factors for survival (Table V).

\section{DISCUSSION}

The initial management of limited ITMs without signs of disseminated disease is local treatment, for example, surgical excision, cryosurgery, laser ablation, intralesional therapy, electrochemotherapy, and/or radiation \pm hyperthermia (Fig. 1) [34]. If ITMs recur, local treatment is applied as long as possible. The disease free interval cannot be predicted and favorable immune responses are sporadically seen.

When the disease free interval after local treatment of ITMs in the limb is fast decreasing and/or the number of ITMs is rapidly increasing, i.e. where there is extensive or bulky disease, there may be an indication for regional therapy, for example, ILP or ILI. A drawback of ILP is the invasive and complex character of the procedure. ILI is as a minimally invasive alternative to ILP. There is no substantial difference in the DFS after ILP or ILI when melphalan is used [35]. Before initiating a regional therapy these IIIB/C patients are staged with FDG-PET and the tumor markers LDH and S100B [11]. There is no indication for a routine MRI of the brain in asymptomatic stage III melanoma patients [36]. Patients with disseminated disease are usually treated with systemic therapy, although there is sometimes an indication for a palliative ILP or ILI [37,38]. With M-ILP or M-ILI for ITMs remarkably effective regional control is achieved, but there is still a need for further therapeutic improvement [39]. TM-ILP has been shown to be an extremely effective limb salvage procedure for locally advanced sarcomas, but there is only a limited experience with TM-ILP for locally advanced ITMs [40].

$\mathrm{TNF} \alpha$ in combination with melphalan can only be used in the regional setting, since TNF $\alpha$ plays a key role as a polypeptide mediator in the pathogenesis of septic shock [41]. TNF $\alpha$ is a vasoactive drug that causes destruction of the tumor vasculature in tumors that are highly vascularized and increases intratumoral vessel permeability, facilitating 3- to 6-fold higher drug uptake of melphalan in the tumor [42]. This is the

TABLE IV. Complete Response, Age and Number of ITMs

\begin{tabular}{|c|c|c|c|c|}
\hline ILP & $\begin{array}{c}\text { M-ILP }(\mathrm{n}=6) \\
(\mathrm{No}, \%)\end{array}$ & $\begin{array}{l}\text { TM-ILP }(\mathrm{n}=21) \\
(\mathrm{No}, \%)\end{array}$ & $\begin{array}{c}\text { Total }(\mathrm{n}=27) \\
(\mathrm{No}, \%)\end{array}$ & $P$-value \\
\hline \multicolumn{5}{|l|}{ Age } \\
\hline$<65$ years & $5(56 \%)$ & $13(77 \%)$ & $18(69 \%)$ & 0.003 \\
\hline$\geq 65$ years & $1(11 \%)$ & $8(36 \%)$ & $9(29 \%)$ & \\
\hline \multicolumn{5}{|c|}{ Number of ITMs } \\
\hline 1-5 ITMs & $1(100 \%)$ & $8(73 \%)$ & $9(75 \%)$ & 0.038 \\
\hline$>5$ ITMs & $5(29 \%)$ & $13(48 \%)$ & $18(41 \%)$ & \\
\hline
\end{tabular}




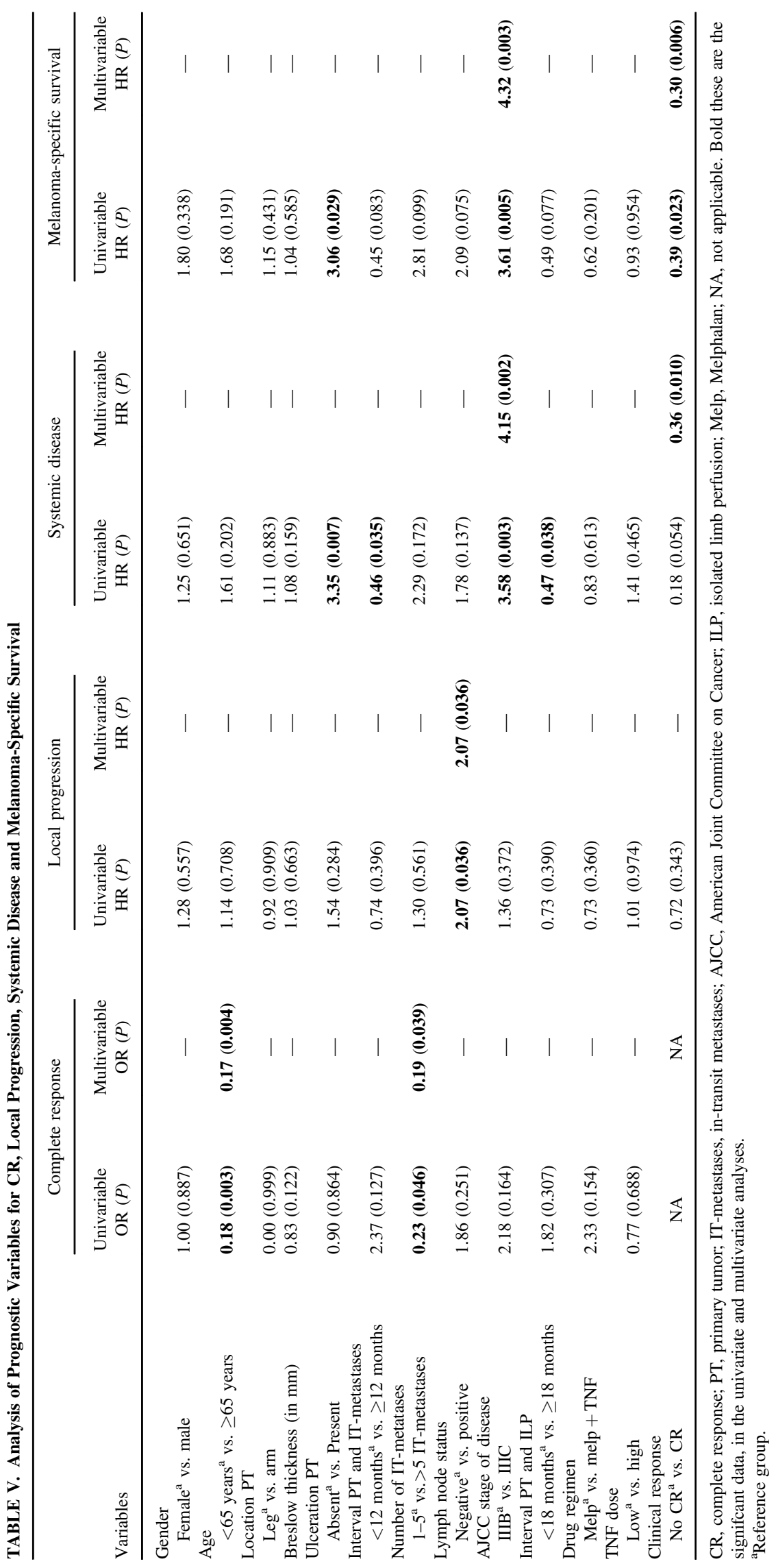


A

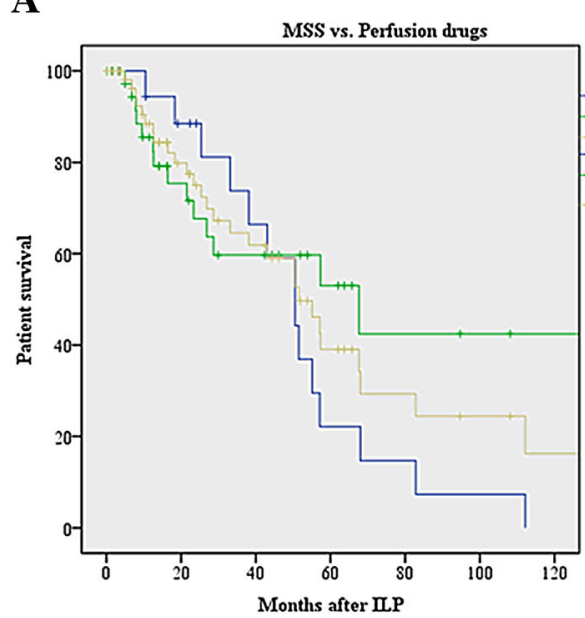

C

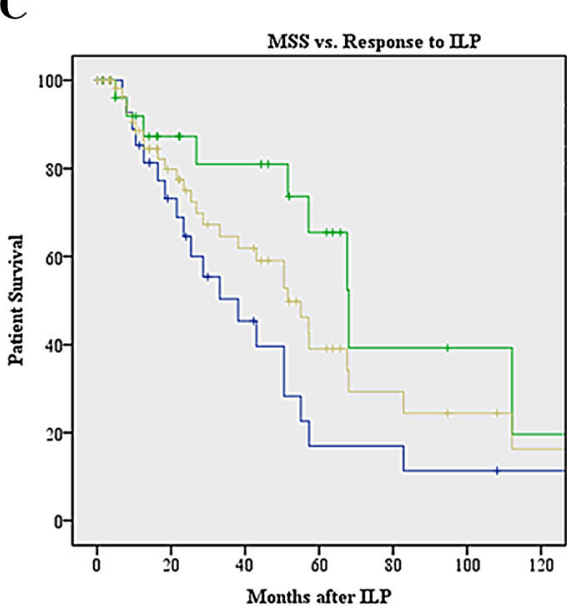

$P=0.196$

PF drigs תM-ILP 7 TM-ILP
Total population -M.ILP.censored TM-ILP.censored Total population. censored (a)

\section{.}

B

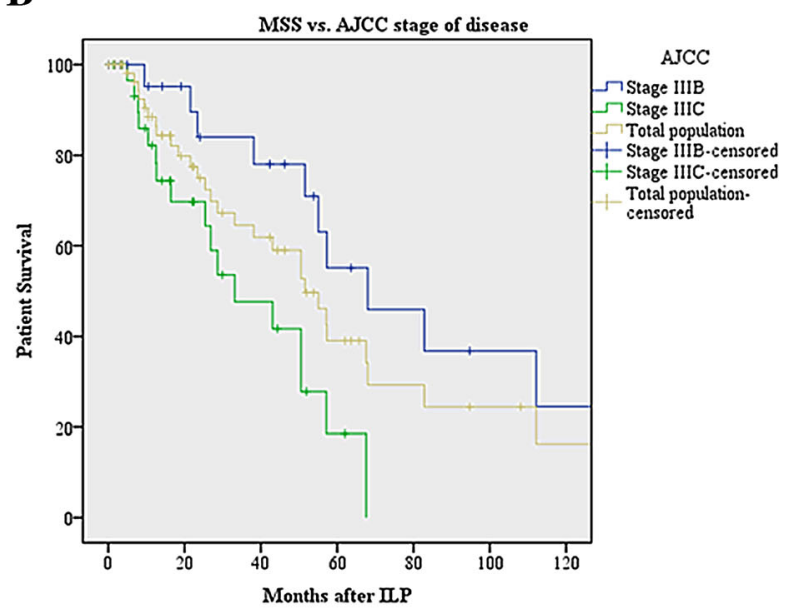

$P=0.018 \quad$ D

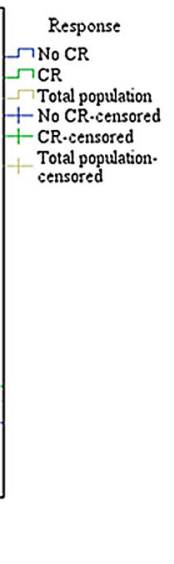

Fig. 4. Melanoma-specific survival: (A) MSS versus perfusion drugs; (B) MSS versus AJCC stage of disease; (C) MSS versus complete response; (D) MSS versus ulceration.

rationale for using M-ILP for "limited disease" and TM-ILP for the more vascularized "bulky disease." One of the disadvantages of TM-ILP is the systemic toxicity which is significantly correlated with high TNF $\alpha$ doses [43]. This was the major reason for the perfusion centers in Rotterdam and Groningen to lower the TNF $\alpha$ dose a decade ago. The reduced perfusion time with $\mathrm{TNF} \alpha$ and melphalan and the better washout with an increased volume of saline resulted in decreased cardiovascular instability of the perfused patient during and after TMILP [44].

One clinical dose-finding study for TNF $\alpha$ in TM-ILP for melanoma was performed and two groups reported the use of low dose TNF $\alpha$ in ILP [45-49]. Escalating the TNF dose to $6 \mathrm{mg}$ did not increase the complete response rate, but increased regional toxicity [45]. Grünhagen et al. [47] showed in a series of 100 TM-ILPs for melanoma ITMs that TNF $\alpha$ dose reduction did not alter the ILP outcome with respect to overall response or disease outcome The TNF $\alpha$ dose reduction reduced perfusion cost by 3,000-4,000 per ILP procedure. A recent update of this study showed however that larger doses of TNF $\alpha$ were significantly more effective in achieving CRs ( $70 \%$ vs. $49 \%, P<0.006)$. Nevertheless, the high percentage of CRs achieved with high-dose TNF $\alpha$ did not translate into a prolongation of OS (16 vs. 11 months, $P=0.076)$ [49].

There are limited data about the use of TM-ILP for ITMs in melanoma patients, as shown in Table VI. There has been only one randomized trial, the ACSOG Z0020 trial, and four retrospective studies comparing M-ILP versus TM-ILP, plus the current series [46,55-58]. The initial results of the ACSOG Z0020 trial published in an abstract were more impressive than the final results [57,59]. The results of the retrospective non-randomized studies showed more CRs after TM-ILP overall, in contrast to Cornett who found no significant difference in the CR rate after 3 months [46,55-58]. However, the CR rate in the Cornett series was extremely low in comparison to the $\mathrm{CR}$ rates reported by others and summarized in Table VI.

There is no higher regional complication rate after TM-ILP compared to M-ILP [65]. Therefore double perfusions with TM-ILP can be performed. This is the main reason that most perfusion centers start to perfuse (1) at the most distant perfusion level which is possible and, if indicated, a second perfusion can be performed more proximally and (2) start with M-ILP, if possible, so that a second ILP with TNF $\alpha$ and melphalan can be performed if necessary for recurrent disease.

Although TNF $\alpha$ (Beromun ${ }^{\mathbb{R}}$ ) is registered in Europe [27], it is not FDA-approved. The FDAs's attitude is mainly based on the preliminary results of the multi-institutional study and ACOSOG trial, which was closed early after an interim analysis showed no evidence of improved responses after 3 months. This decision was extensive criticized. However, a recent large single center study also failed to show improvement in regional in-field progression-free survival [63]. 
TABLE VI. Therapeutic TM-ILPs for In-Transit Metastases

\begin{tabular}{|c|c|c|c|c|c|c|c|c|}
\hline Study & Year & Refs. & Design & Perfusion treatment & $\mathrm{N}$ & Objective & CR & CR \\
\hline Lienard & 1992 & {$[50]$} & Retrospective & Melphalan and TNF $\alpha$ & 19 & $100 \%$ & $89 \%$ & \\
\hline Lejeune & 1993 & [51] & Retrospective & Melphalan and TNF $\alpha$ & 44 & $100 \%$ & $90 \%$ & \\
\hline Lienard & 1994 & [52] & Retrospective & Melphalan and $\mathrm{TNF} \alpha$ & 53 & $100 \%$ & $90 \%$ & \\
\hline Vaglini & 1994 & [53] & Retrospective & Melphalan and $\mathrm{TNF} \alpha$ & 22 & $77 \%$ & $64 \%$ & \\
\hline Eggermont & 1995 & [54] & Retrospective & Melphalan and $\mathrm{TNF} \alpha$ & 22 & $100 \%$ & $88 \%$ & \\
\hline Fraker & 1996 & [45] & Retrospective & Melphalan and TNF $\alpha$ & 26 & $92 \%$ & $76 \%$ & \\
\hline Bartlett & 1997 & {$[55]$} & Retrospective & Melphalan and TNF $\alpha$ & 58 & $94 \%$ & $65 \%$ & \\
\hline Lienard & 1999 & [56] & Retrospective & Melphalan $\pm \mathrm{TNF} \alpha$ & 167 & $95 \%$ & $73 \%$ & $52 \%$ vs $73 \%$ \\
\hline Fraker & 2002 & [57] & $\mathrm{RCT}$ & Melphalan $\pm \mathrm{TNF} \alpha$ & 103 & - & - & $58 \%$ vs $72 \%$ \\
\hline Noorda & 2004 & [58] & Retrospective & Melphalan $\pm \mathrm{TNF} \alpha$ & 130 & $77 \%$ & $55 \%$ & $45 \%$ vs $59 \%$ \\
\hline Grunhagen & 2004 & {$[47]$} & Retrospective & Melphalan and TNF $\alpha$ & 100 & $95 \%$ & $69 \%$ & \\
\hline Rossi & 2004 & [48] & Retrospective & Melphalan and TNF $\alpha$ & 20 & $95 \%$ & $70 \%$ & \\
\hline Cornett & 2006 & [59] & $\mathrm{RCT}$ & Melphalan $\pm \mathrm{TNF} \alpha$ & 124 & - & - & $25 \%$ vs $26 \%$ \\
\hline Hayes & 2007 & [60] & Retrospective & Melphalan and TNF $\alpha$ & 27 & $77 \%$ & $41 \%$ & \\
\hline Rossi & 2008 & {$[61]$} & Retrospective & Melphalan and $\mathrm{TNF} \alpha$ & 31 & - & $2 \%$ & \\
\hline Di Filippo & 2009 & [62] & Retrospective & Melphalan and TNF $\alpha$ & 113 & $88 \%$ & $63 \%$ & \\
\hline Alexander & 2010 & {$[63]$} & Retrospective & Melphalan and $\mathrm{TNF} \alpha$ & 91 & $95 \%$ & $69 \%$ & \\
\hline Rossi & 2010 & [46] & Retrospective & Melphalan $\pm \mathrm{TNF} \alpha$ & 112 & $90 \%$ & $51 \%$ & $40 \%$ vs $60 \%$ \\
\hline Deroose & 2011 & {$[64]$} & Retrospective & Melphalan and TNF $\alpha$ & 105 & $93 \%$ & $68 \%$ & \\
\hline Deroose & 2012 & [49] & Retrospective & Melphalan and TNF $\alpha$ & 167 & $89 \%$ & $61 \%$ & \\
\hline Hoekstra $^{a}$ & 2014 & & Retrospective & Melphalan $\pm \mathrm{TNF} \alpha$ & 57 & $90 \%$ & $45 \%$ & $32 \%$ vs $51 \%$ \\
\hline
\end{tabular}

TM-ILPs, tumor necrosis factor alpha and melphalan isolated limb perfusion; CR, complete response; Ref, references.

${ }^{\mathrm{a} C}$ Current series.

In conclusion, the current study and the M-ILP and TM-ILP literature show clearly that the longer the time interval between primary tumor treatment and the development of ITMs and the smaller the tumor load the better the MSS and overall survival. TM-ILP and TM-ILI are effective regional treatments for ITMs of melanoma, without a substantial difference in outcome. The first ILP option is a M-ILP, whereas for bulky disease TM-ILP should be the first choice, since reponses for TM-ILP are overall better than M-ILP. The regional in-field progression-free survival after regional therapy is determined (1) by the biological behavior of the ITMs and (2) the patient's immune system.

For patients who are not candidates for regional M-ILP, TM-ILP or M-ILI therapy, novel promising local therapies are currently being tested in phase II and phase III trials. Such novel therapies include intralesional therapy with Rose Bengal for chemoablation of ITMs [66]. It will also be essential to study the effect of new systemic therapies, such as drugtargeted BRAF and/or MEK inhibitors as well as immune targeting therapy in ITM patients.

The introduction of TM-ILP 25 years ago for the treatment of ITMs was exciting. Today we have further exciting new treatments, for example, drug-targeting and immune targeting therapies, for advanced melanoma. Whether these systemic treatments will have the same or better local effects on melanoma ITMs will be studied in the coming years. Until then, regional therapy with TM-ILP will remain an effective local therapy for locally advanced melanoma confined to a limb, with acceptable morbidity and a high limb salvage rate.

\section{REFERENCES}

1. Kruijff S, Bastiaannet E, Francken AB, et al.: Breslow thickness in the Netherlands: A population-based study of 40880 patients comparing young and elderly patients. Br J Cancer 2012;107:570574.

2. http://seer.cancer.gov.

3. http://canceraustralia.gov.au.

4. Speijers MJ, Francken AB, Hoekstra-Weebers JEHM, et al.: Optimal follow-up for melanoma. Expert Rev Dermatol 2010;5: 461-478.

5. Thompson JF, Soong SJ, Balch CM, et al.: Prognostic significance of mitotic rate in localized primary cutaneous melanoma: An analysis of patients in the multi-institutional American Joint Committee on Cancer melanoma staging database. J Clin Oncol 2011;29:2199-2205.

6. Morton DL, Hoon DS, Cochran AJ, et al.: Lymphatic mapping and sentinel lymphadenectomy for early-stage melanoma: Therapeutic utility and implications of nodal microanatomy and molecular staging for improving the accuracy of detection of nodal micrometastases. Ann Surg 2003;238:538-549,discussion 549-550.

7. Borgstein PJ, Meijer S, van Diest PJ: Are locoregional cutaneous metastases in melanoma predictable? Ann Surg Oncol 1999;6:315-321.

8. Stucky CC, Gray RJ, Dueck AC, et al.: Risk factors associated with local and in-transit recurrence of cutaneous melanoma. Am J Surg 2010;200:770-774,discussion 774-775.

9. Francken AB, Bastiaannet E: Hoekstra HJ Follow-up in patients with localised primary cutaneous melanoma. Lancet Oncol 2005;6: 608-621.

10. Schraffordt Koops H, Vaglini M, Suciu S, et al.: Prophylactic isolated limb perfusion for localized, high-risk limb melanoma: Results of a multicenter randomized phase III trial. European Organization for Research and Treatment of Cancer Malignant Melanoma Cooperative Group Protocol 18832, the World Health Organization Melanoma Program Trial 15, and the North American Perfusion Group Southwest Oncology Group-8593. J Clin Oncol 1998;16:2906-2912.

11. Niebling MG, Bastiaannet E, Hoekstra OS, et al.: Outcome of clinical stage III melanoma patients with FDG-PET and whole-body CT added to the diagnostic workup. Ann Surg Oncol 2013; 20:3098-3105.

12. Howard JH, Thompson JF, Mozzillo N, et al.: Metastasectomy for distant metastatic melanoma: Analysis of data from the first Multicenter Selective Lymphadenectomy Trial (MSLT-I). Ann Surg Oncol 2012;19:2547-2555.

13. Wevers KP, Hoekstra HJ: Stage IV Melanoma: Completely resectable patients are scarce. Ann Surg Oncol 2013;20:2352-2356.

14. Hodi FS, O'Day SJ, McDermott DF, et al.: Improved survival with ipilimumab in patients with metastatic melanoma. N Engl J Med 2010;363:711-723.

15. Chapman PB, Hauschild A, Robert $C$, et al.: Improved survival with vemurafenib in melanoma with BRAF V600E mutation. N Engl J Med 2011;364:2507-2516.

16. Flaherty KT, Robert C, Hersey P, et al.: Improved survival with MEK inhibition in BRAF-mutated melanoma. $\mathrm{N}$ Engl $\mathrm{J}$ Med 2012;367:107-114J 
17. Hamid O, Robert C, Daud A, et al.: et al. Safety and tumor responses with Lambrolizumab (Anti-PD-1) in melanoma. N Eng J Med 2013; 369:134-144.

18. Pawlik TM, Ross MI, Thompson JF, et al.: The risk of in-transit melanoma metastasis depends on tumor biology and not the surgical approach to regional lymph nodes. J Clin Oncol 2005;23:45884590.

19. Nieweg OE, Kroon BBR: Isolated limb perfusion with melphalan for melanoma. J Surg Oncol 2014, in press.

20. Kroon HM, Moncrieff M, Kam PC, et al.: Outcomes following isolated limb infusion for melanoma. A 14-year experience. Ann Surg Oncol 2008;15:3003-3013.

21. Hoekstra HJ, Schraffordt Koops H, de Vries EGE, et al.: Toxicity of hyperthermic isolated limb perfusion with cisplatin for recurrent melanoma of the lower extremity after previous perfusion treatment. Cancer 1993;72:1224-1229.

22. Daryanani D, de Vries EG, Guchelaar HJ, et al.: Hyperthermic isolated regional perfusion of the limb with carboplatin. Eur J Surg Oncol 2000;26:792-797.

23. Lejeune F: Locoregional use of TNF (tumor necrosis factor) in the treatment of malignant melanoma. Pathol Biol 1990;38:883884 .

24. Liénard D, Eggermont AM, Schraffordt Koops H, et al.: Isolated perfusion of the limb with high-dose tumour necrosis factor-alpha (TNF-alpha), interferon-gamma (IFN-gamma) and melphalan for melanoma stage III. Results of a multi-centre pilot study. Melanoma Res 1994;21-26.

25. Eggermont AM, Schraffordt Koops H, Liénard D, et al.: Isolated limb perfusion with high-dose tumor necrosis factor-alpha in combination with interferon-gamma and melphalan for nonresectable extremity soft tissue sarcomas: A multicenter trial. J Clin Oncol 1996;14:2653-2665.

26. Eggermont AM, Schraffordt Koops H, Klausner JM, et al.: Isolated limb perfusion with tumor necrosis factor and melphalan for limb salvage in 186 patients with locally advanced soft tissue extremity sarcomas. The cumulative multicenter European experience. Ann Surg 1996;224:756-764, discussion 764-765.

27. http://www.ema.europa.eu.

28. Fontijne WP, de Vries J, Mook PH, et al.: Improved tissue perfusion during pressure-regulated hyperthermic regional isolated perfusion in dogs. J Surg Oncol 1984;26:69-76.

29. Daryanani D, Komdeur R, Ter Veen J, et al.: Continuous leakage measurement during hyperthermic isolated limb perfusion. Ann Surg Oncol 2001;8:566-572.

30. van Os J, Schraffordt Koops H, Oldhoff J: Dosimetry of cytostatics in hyperthermic regional isolated perfusion. Cancer 1985;55:698701 .

31. Hoekstra HJ: Isolated limb perfusion. In: Audiso RA, editor. Atlas of surgical procedures in surgical oncology with critical, evidencebased commentary notes. Singapore: World Scientific Publishers; 2010.pp. 259-265.

32. Therasse P, Arbuck SG, Eisenhauer EA, et al.: New guidelines to evaluate the response to treatment in solid tumors. European Organization for Research and Treatment of Cancer, National Cancer Institute of the United States, National Cancer Institute of Canada. J Natl Cancer Inst 2000;92:205-216.

33. Wieberdink J, Benckhuysen C, Braat RP, et al.: Dosimetry in isolation perfusion of the limbs by assessment of perfused tissue volume and grading of toxic tissue reactions. Eur J Cancer Clin Oncol 1982;18:905-910.

34. Hoekstra HJ: The European approach to in-transit melanoma lesions. Int J Hyperthermia 2008;24:227-237.

35. Kroon HM, Thompson JF: Isolated limb infusion: A review. J Surg Oncol 2009;100:169-177.

36. Aloia TA, Gershenwald JE, Andtbacka RH, et al.: Utility of computed tomography and magnetic resonance imaging staging before completion lymphadenectomy in patients with sentinel lymph node-positive melanoma. J Clin Oncol 2006;24:2858-2865.

37. Grunhagen DJ, de Wilt JH, Graveland WJ, et al.: The palliative value of tumor necrosis factor alpha-based isolated limb perfusion in patients with metastatic sarcoma and melanoma. Cancer 2006; 106:156-162.
38. Kroon HM, Lin DY, Kam PC, et al.: Isolated limb infusion as palliative treatment for advanced limb disease in patients with AJCC stage IV melanoma. Ann Surg Oncol 2009;16:1193-1201.

39. Testori A, Verhoef C, Kroon HM, et al.: Treatment of melanoma metastases in a limb by isolated limb perfusion and isolated limb infusion. J Surg Oncol 2011;104:397-404.

40. Seinen JM, Hoekstra HJ: Isolated limb perfusion of soft tissue sarcomas: A comprehensive review of literature. Cancer Treat Rev 2013;39:569-577.

41. Glauser MP, Zanetti G, Baumgartner JD, et al.: Septic shock: Pathogenesis. Lancet 1991;338:732-736.

42. Nooijen PT, Manusama ER, Eggermont AM, et al.: Synergistic effects of TNF-alpha and melphalan in an isolated limb perfusion model of rat sarcoma: A histopathological, immunohistochemical and electron microscopical study. Br J Cancer 1996;74:19081915.

43. Zwaveling JH, Maring JK, Clarke FL, et al.: High plasma tumor necrosis factor (TNF)-alpha concentrations and a sepsis-like syndrome in patients undergoing hyperthermic isolated limb perfusion with recombinant TNF-alpha, interferon-gamma, and melphalan. Crit Care Med 1996;24:765-770.

44. Lejeune F, Liénard D, Eggermont A, et al.: Clinical experience with high-dose tumor necrosis factor alpha in regional therapy of advanced melanoma. Circ Shock 1994;43:191-197.

45. Fraker DL, Alexander HR, Andrich M: Rosenberg SA teatment of patients with melanoma of the extremity using hyperthermic isolated limb perfusion with melphalan, tumor necrosis factor, and interferon gamma: Results of a tumor necrosis factor doseescalation study. J Clin Oncol 1996;14:479-489.

46. Rossi CR, Pasquali S, Mocellin S, et al.: Long-term results of melphalan-based isolated limb perfusion with or without low-dose TNF for in-transit melanoma metastases. Ann Surg Oncol 2010;17:3000-3007.

47. Grünhagen DJ, Brunstein F, Graveland WJ, et al.: One hundred consecutive isolated limb perfusions with TNF-alpha and melphalan in melanoma patients with multiple in-transit metastases. Ann Surg 2004;240:939-947,discussion 947-948.

48. Rossi CR, Foletto M, Mocellin S, et al.: Hyperthermic isolated limb perfusion with low-dose tumor necrosis factor-alpha and melphalan for bulky in-transit melanoma metastases. Ann Surg Oncol 2004;11:173-177.

49. Deroose JP, Eggermont AM, van Geel AN, et al.: 20 years experience of TNF-based isolated limb perfusion for in-transit melanoma metastases: TNF dose matters. Ann Surg Oncol 2012; 19:627-635.

50. Lienard D, Ewalenko P, Delmotte JJ, et al.: High-dose recombinant tumor necrosis factor alpha in combination with interferon gamma and melphalan in isolation perfusion of the limbs for melanoma and sarcoma. J Clin Oncol 1992;10:52-60.

51. Lejeune FJ, Liénard D, Leyvraz S, et al.: Regional therapy of melanoma. Eur J Cancer 1993;29A:606-612.

52. Liénard D, Eggermont AM, Schraffordt Koops H, et al.: Isolated perfusion of the limb with high-dose tumour necrosis factor-alpha (TNF-alpha), interferon-gamma (IFN-gamma) and melphalan for melanoma stage III. Results of a multi-centre pilot study. Melanoma Res 1994;4:21-26.

53. Vaglini M, Santinami M, Manzi R, et al.: Treatment of in-transit metastases from cutaneous melanoma by isolation perfusion with tumour necrosis factor-alpha (TNF-alpha), melphalan and interferon-gamma (IFN-gamma. Dose-finding experience at the National Cancer Institute of Milan. Melanoma Res 1994;4:35-38.

54. Eggermont AM, Lienard D, Schraffordt Koops H, et al.: High dose tumor necrosis factor-alpha in isolated perfusion of the limb: Highly effective treatment for melanoma in in-transit metastases or unresectable sarcoma. Reg Cancer Treat 1995;7:32-36.

55. Bartlett DL, Ma G, Alexander HR, et al.: Isolated limb reperfusion with tumor necrosis factor and melphalan in patients with extremity melanoma after failure of isolated limb perfusion with chemotherapeutics. Cancer 1997;80:2084-2090.

56. Liénard D, Eggermont AM, Koops HS, et al.: Isolated limb perfusion with tumour necrosis factor-alpha and melphalan with or without interferon-gamma for the treatment of in-transit melanoma 
metastases: A multicentre randomized phase II study. Melanoma Res 1999;9:491-502.

57. Fraker D1, Alexander H, Ross M, et al.: A trial of isolated limb perfusion for extremity melanoma comparing melphalan versus melphalan plus tumor necrosis factor (TNF) plus interferon gamma. Ann Surg Oncol 2002;9:S8.

58. Noorda EM, Vrouenraets BC, Nieweg OE, et al.: Isolated limb perfusion for unresectable melanoma of the extremities. Arch Surg 2004;139:1237-1242.

59. Cornett WR, McCall LM, Petersen RP, et al.: Randomized multicenter trial of hyperthermic isolated limb perfusion with melphalan alone compared with melphalan plus tumor necrosis factor: American College of Surgeons Oncology Group Trial Z0020. J Clin Oncol 2006;24:4196-4201.

60. Hayes AJ, Neuhaus SJ, Clark MA, et al.: Isolated limb perfusion with melphalan and tumor necrosis factor alpha for advanced melanoma and soft-tissue sarcoma. Ann Surg Oncol 2007;14:230-238.

61. Rossi CR, Russano F, Mocellin S, et al.: TNF-based isolated limb perfusion followed by consolidation biotherapy with systemic lowdose interferon alpha $2 \mathrm{~b}$ in patients with in-transit melanoma metastases: A pilot trial. Ann Surg Oncol 2008;15:1218-1223.
62. Di Fillipo F, Giacomini P, Rossi CR, et al.: Prognostic factors influencing tumor response, locoregional control and survival, in melanoma patients with multiple limb in-transit metastases treated with TNFalpha-based isolated limb perfusion. In Vivo 2009;23: 347-352.

63. Alexander HR, Jr., Fraker DL, Bartlett DL, et al.: Analysis of factors influencing outcome in patients with in-transit malignant melanoma undergoing isolated limb perfusion using modern treatment parameters. J Clin Oncol 2010;28:114118.

64. Deroose JP, Grünhagen DJ, van Geel AN, et al.: Long-term outcome of isolated limb perfusion with tumour necrosis factor- $\alpha$ for patients with melanoma in-transit metastases. Br J Surg 2011;98:1573-1580.

65. Vrouenraets BC, Eggermont AM, Hart AA: Regional toxicity after isolated limb perfusion with melphalan and tumour necrosis factoralpha versus toxicity after melphalan alone. Eur J Surg Oncol 2001;27:390-395.

66. Thompson JF, Hersey P, Wachter E: Chemoablation of metastatic melanoma using intralesional Rose Bengal. Melanoma Res 2008;18:405-411. 